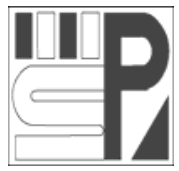

Science Press
J ournal of Arid Land

2011, 3(3): 184-190

doi: 10.3724/SP.J.1227.2011.00184

jal.xjegi.com; www.chiansciencejournal.com

\title{
Magnetostratigraphy and provenance of the Qingzhou loess in Shandong province
}

\author{
ShuZhen PENG ${ }^{1,2^{*}}$, LiJun ZHU ${ }^{2}$, GuoQiao XIAO ${ }^{3}$, YanSong QIAO ${ }^{4}$, ZhiDong GAO ${ }^{2}$, DongDong $\mathrm{CHEN}^{2}$ \\ ${ }^{1}$ Department of Tourism, Resources and Environment, Taishan University, Taian 271021, China; \\ ${ }^{2}$ College of Urban and Environment Sciences of Shanxi Normal University, Linfen 041000, China; \\ ${ }^{3}$ Key Laboratory of Biogeology and Environmental Geology of Ministry of Education, China University of Geosciences, Wuhan \\ 430074, China; \\ ${ }^{4}$ Institute of Geomechanics, Chinese Academy of Geological Sciences, Beijing 100081, China
}

\begin{abstract}
Loess deposits with varying thickness are widely distributed on the intermontane valleys and piedmont zones on the northern side of the central Shandong mountainous regions. However, the basal ages and material resources of the loess deposits are not clear. The paper studied the Qingzhou loess profile in Shandong with magnetostratigraphic and optical stimulated luminescence (OSL) methods and further investigated its main provenances with the mineralogical methods. The magnetostratigraphic results showed that the Brunhes/Matuyama (B/M) reversal boundary was not recognized, suggesting a basal age younger than $0.78 \mathrm{Ma}$. Extrapolations by sedimentation rates, based on the upper part depositional rate from the OSL age, the basal age of the Qingzhou loess is about 0.5 Ma. Until now, older loess deposits have not been reported on the northern side of the central Shandong mountainous regions. The results of the paper indicate that the loess deposits in this area might have strated from the Middle Pleistocene. The basal age of Qingzhou loess is approximately synchronous with the Xiashu loess in the middle-lower reaches of Yangtze River. Major components of clay minerals in the Qingzhou profile are dominated by illite. Other clay mineral compositions are mainly smectite, chlorite and kaolinite, which are similar with the Xifeng loess in the Loess Plateau. However, the contents of smectite and the ratios of illite and kaolinte in the Qingzhou loess samples are higher than those in the Xifeng loess samples of the Loess Plateau, indicating that the loess in the northern side of the central Shandong mountainous regions has different sources from that of the loess deposits in the Loess Plateau. The clay mineral analysis further reinforces the earlier conclusion that the marine strata exposed in the Laizhou Bay and the fluvial plain of the lower reaches of Yellow River during the glacier periods are the main material sources for the Qingzhou loess deposits, which is an indicator to the local aridification of the lower reaches of the Yellow River. Loess deposition in the central Shandong mountainous regions started at around $0.5 \mathrm{Ma}$. The age of Qingzhou loess is approximately synchronous with the ongoing high-latitude cold since the Middle Pleistocene, which indicates that strengthened East Asian winter monsoon was sufficiently energetic to bring substantial quantities of material from the marine strata exposed in the Laizhou Bay and the fluvial plain of the lower reaches of the Yellow River to the central Shandong mountainous regions. The results therefore suggest that both regional geological process and global changes were responsible for the formation of Qingzhou loess since Middle Pleistocene.
\end{abstract}

Keywords: Loess; magnetostratigraphy; sedimentology; material provenance; Qingzhou

The Chinese loess is distributed mainly between the north of Kunlun and Qinling mountains and the south of Altai, Alashan and Greater Khingan mountains, presenting a WWN-EES trend loess belt (Liu, 1965, 1985). Shandong province is located on the eastern margin of the loess belt. Based on geomorphic charcteristics, the loess distribution in Shandong province

\footnotetext{
Received 2011-03-18; accepted 2011-03-31

* Corresponding author: ShuZhen Peng (E-mail: shuzhenpeng@sohu.com; pengsz@mail.iggcas.ac.cn)
} 
can be divided into two parts: one is littoral of Bohai Bay and islands region and another is the piedmont of the mountains in middle Shandong province (Cao et al., 1987; Zheng, 1994; Wang et al., 1999; Liu et al., 2000; Zhang et al., 2004; Peng et al., 2007). The loess in the latter region spreads in east-west direction along the north side of hills. The thickness of the loess is varied, and the most are less than $30 \mathrm{~m}$. The stratum of Qingzhou loess is the thickest one and is well preserved. So far, lots of studies about the origin, forming age and material provenance of the Qingzhou loess (Zheng et al., 1994; Liu et al., 2000; Zhang et al., 2004; Peng et al., 2007) were carried out. Field observation and systemic sedimentary analysis have proved the eolian origin of loess (Liu et al., 2000; Zhang et al., 2004; Peng et al., 2007). However, there are controversial results about the chronology study of the Qingzhou loess due to different dating methods (Zheng et al., 1994; Zhang et al., 2004). As for the material provenance, Qingzhou loess have been considered mainly to be from the loose deposits of Yellow River's fluvial plain and to be exposed on Bohai Bay shelf during glacier periods, with little from the remote Asian inland deserts (Cao et al., 1987; Zheng, 1994; Wang et al., 1999; Liu et al., 2000; Zhang et al., 2004; Peng et al., 2007). However, these opinions are mainly based on sedimentary studies. In this paper, we studied a loess profile named Fujia village in Qingzhou, Shandong province. The chronology of this profile was established by magnatostratigraphy and optically stimulated luminescence (OSL) methods. Combined with the early sedimentary studies (Liu et al., 2000; Peng et al., 2007) and the clay mineral analysis in this paper, the paleoenvironmental significance of the Qingzhou loess was discussed.

\section{Study area}

Qingzhou city is located in the mid-west of the Shandong peninsula with a warm temperate and semi-humid climate. The mean annual temperature and precipitation are about $12.7^{\circ} \mathrm{C}$ and $750 \mathrm{~mm}$, respectively. The city prevails northwesterly wind in winter and southeasterly wind in summer, respectively. The loess in Qingzhou mainly spread along the adjacent area between the north margin of the central Shandong Mountains and plain region of northern Shandong province. The research area $\left(36^{\circ} 40^{\prime} \mathrm{N}\right.$, $118^{\circ} 27^{\prime} \mathrm{E}$ ) is located in the west ditch of Fujia village, at the foot of Yunmen Mountain, 2-km southwest of Qingzhou city (Fig. 1).

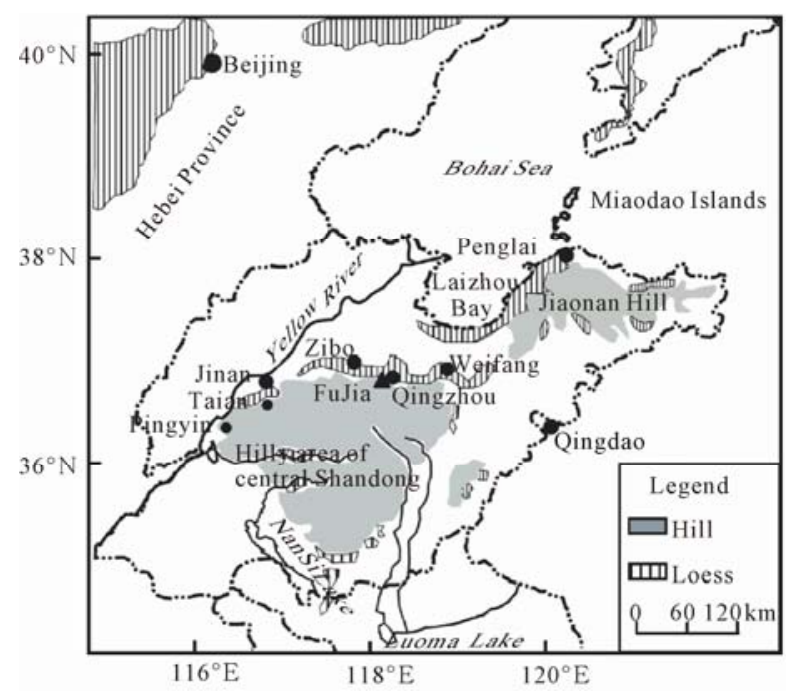

Fig. 1 Schematic map of the study area (modified after Zhang et al., 2004).

The study area is a vertical loess cliff, about $28.2 \mathrm{~m}$ in thickness, and underlain by fluvial sand. Except for a $0.5-1 \mathrm{~m}$ weathering surface layer, the profile can be divided into four parts based on stratigraphic characteristics:

(1) Modern plough horizon. It is $0.85 \mathrm{~m}$ in thickness;

(2) The Holocene loess. It can be sorted into three layers according to the soil development: the upper and lower layers are dark brown soils; the middle layer is loess with lighter color and consists of clayey silts, rich of worm and root holes, and is $2.45 \mathrm{~m}$ in thickness;

(3) Malan loess. It is light yellow, silty sand, rich of joints, and occasionally has calcareous nodules about $1 \mathrm{~cm}$ in diameter, and is $3.7 \mathrm{~m}$ in thickness;

(4) Interbeds of reddish-brown soil and light reddish-brown or light yellow loess. Its color contrasts between soil and loess are not as evident as that of the quaternary loess-like soil in Chinese Loess Plateau. It can be separated into 12 layers of loess and soil in field, respectively. The soil layers of 7.05-8.8 m, 15.3-15.9 $\mathrm{m}$ and 20.2-20.7 $\mathrm{m}$ are darker in color and are easy to be identified. Besides, there are some bedrock particles with a diameter of $2 \mathrm{~mm}$ at $15.9-16.2 \mathrm{~m}$ layer, which may be attributed to the sheet flow carrying particle materials from the surrounding bedrock 
mountains.

\section{Materials and methods}

\subsection{The paleomagnetism samples and measuring}

Based on the detailed field observation to the Qingzhou loess, a total of 92 oriented block samples were collected with sample spacing of $30 \mathrm{~cm}$ for paleomagnetic investigation. In addition, 564 samples at 5-cm intervals were collected for the analyses of magnetic susceptibility, using a Bartington MS2 meter. In the laboratory, all the block samples were cut into oriented cubic specimens with 2-cm edge length for measurement. All samples were subjected to progressive thermal demagnetization using MMTD-80 thermal demagnetizer (Magnetic Measurements Ltd., UK). Thermal demagnetization was performed in steps of $50^{\circ} \mathrm{C}$ to $500^{\circ} \mathrm{C}$, and subsequently in steps of $25^{\circ} \mathrm{C}$ to $585^{\circ} \mathrm{C}$. Remanence measurements were made using a 2G-760 U-Channel system manufactured by US $2 \mathrm{G}$ Company and performed in the Paleomagnetism and Geochronology Laboratory of the Institute of Geology and Geophysics, Chinese Academy of Sciences, China, where all equipment are installed in a magnetically shielded room (background field $<300 \mathrm{nT}$ ).

Demagnetization results were evaluated on stereographic projections and vector end point orthogonal diagrams. The characteristic remanent magnetization (ChRM) directions were calculated by a "least-squares fitting" method (Kirschvink, 1980) with a minimum of five consecutive steps. Typical natural demagnetization diagrams (NRM) are shown in Fig. 2a-f. For most of the samples, a viscous magnetization component can be removed below $150-200^{\circ} \mathrm{C}$, and a ChRM component was successfully isolated between $200^{\circ} \mathrm{C}$ and $550^{\circ} \mathrm{C}$, with no remanence at $585^{\circ} \mathrm{C}$ (Fig. $2 \mathrm{a}-\mathrm{f}$ ),

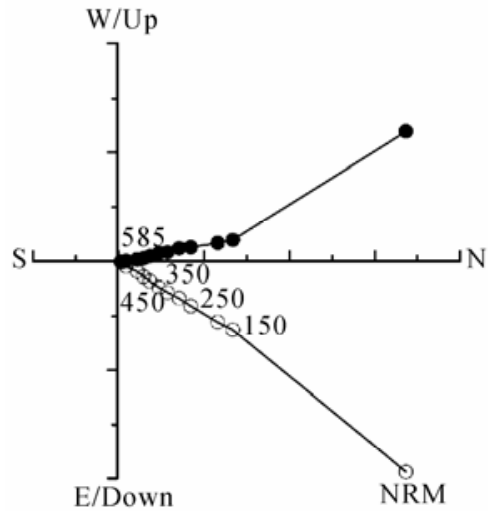

(a) $1.9 \mathrm{~m}$

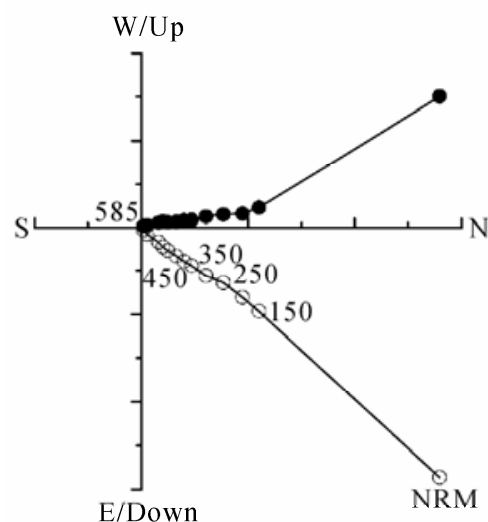

(d) $10.8 \mathrm{~m}$

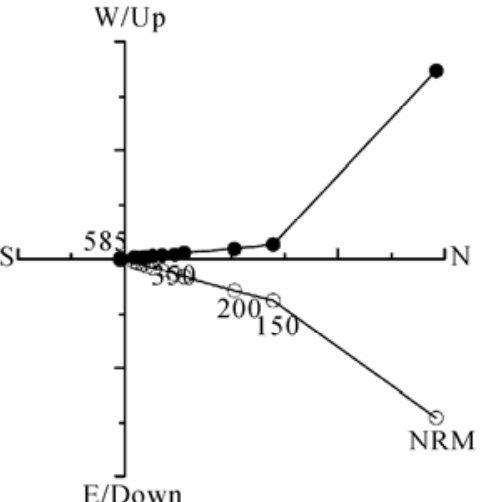

(b) $2.6 \mathrm{~m}$

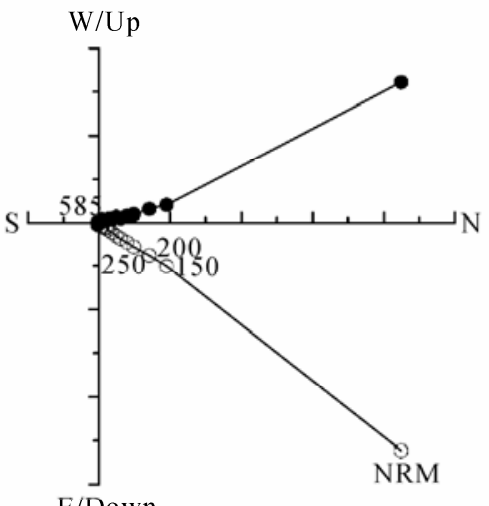

(e) $13.8 \mathrm{~m}$

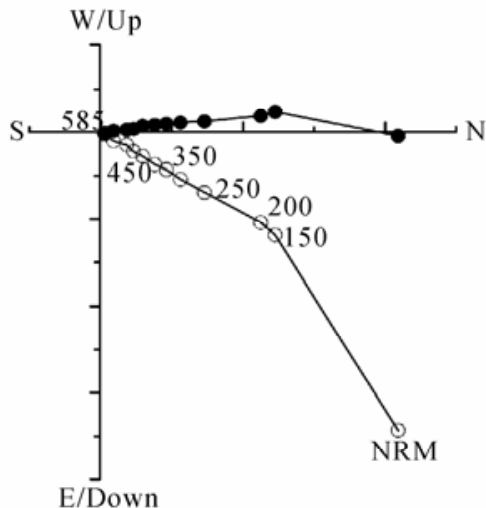

(c) $5.9 \mathrm{~m}$

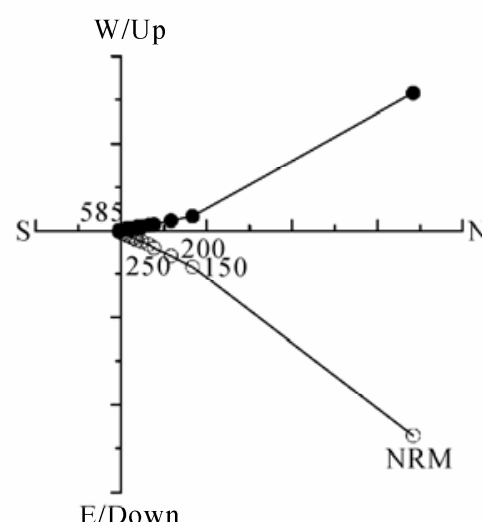

(f) $19.9 \mathrm{~m}$

Fig. 2 Orthogonal vector plots of representative specimens from the Qingzhou loess profile. Solid and open circles represent vector endpoints projected onto horizontal and vertical planes, respectively. NRM means natural remanent magnetization. 
which suggests the magnetic mineral in the study profile is magnetite. Only two samples showed unstable demagnetization trajectories so that ChRM directions could not be isolated.

\subsection{Sampling and experiments of optically stimu- lated luminescence and clay minerals}

Optically stimulated luminescence (OSL) dating method has been widely used in loess chronological studies (Stevens et al., 1989; Lu et al., 2004). The buried time of loess can be calculated from total absorbed radiation dose divided by radiation dose rate. Total absorbed radiation dose is determined by existed specific minerals extracted from the sample with light and measuring the light emitted as a result. Three OSL samples were collected from the upper $10.5-\mathrm{m}$ layer, then quickly wrapped and sealed up by black plastic preservative film for preventing from exposal and evaporation. The OSL was measured in the OSL dating laboratory in the Institute of Earth Environment, Chinese Academy of Sciences.

The analysis of clay minerals in sediments has been extensively applied in tracing and researching the evolvement of the paleoenvironment (Liu et al., 1985; Chamley, 1989; Peng et al., 2007). In order to further tracing the material provenance of the Qingzhou loess, two samples were collected from the unweathered loess layers for clay mineral analysis. The experimental procedure and data processing were determined according to Peng et al. (2007). The clay minerals were detected on X-ray diffraction in the same institute.

\section{Results}

\subsection{The chronology of Qingzhou loess}

The OSL results were shown in Table 1 and Fig. 3. The OSL age for the Holocene soils, $\mathrm{S}_{01}(2.1 \mathrm{~m})$ is about $9.7 \mathrm{ka}$, close to the previous thermal luminescence (TL) age of $12.2 \mathrm{ka}$ for $\mathrm{S}_{02}$, and the age for the boundary of Malan loess and underlying paleosol is about $74.8 \mathrm{ka}$, close to the basal age of the Malan loess in the Chinese Loess Plateau ( $\mathrm{Lu}$ and Zhao,
1991), suggesting this paleosol was formed during the last interglacial period. The measured OSL age also indicates that the loess at the depth of $10.5 \mathrm{~m}$ is about 185 ka old.

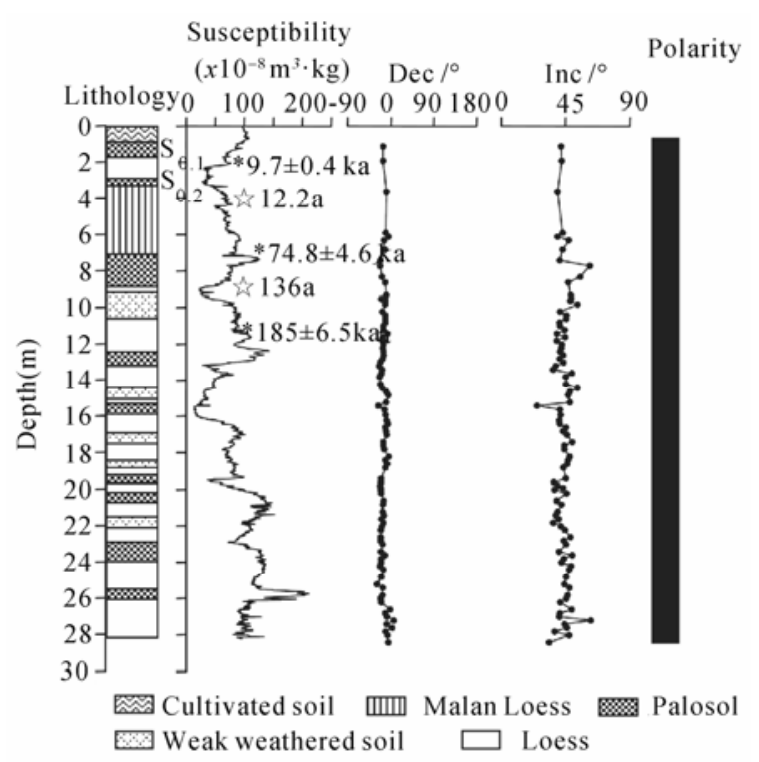

Fig. 3 Lithostratigraphy and magnetostratigraphy of the Qingzhou loess profile; *OSL ages in this study, $\underset{\sim}{\mathrm{O} O S L}$ ages from Liu et al. (2000)

The detailed magnetostratigraphic results showed that the Brunhes/Matuyama (B/M) reversal boundary is not recognized (Fig. 3), suggesting a basal age younger than $0.78 \mathrm{Ma}$. The result is consistent with the previous study (Liu et al., 2000). By linear-extrapolation of the sedimentation rate based on the OSL ages, the basal age of the Qingzhou loess was calculated as $500 \mathrm{ka}$, consistent with the magnetostratigraphic results, thus further supporting the previous study (Liu et al., 2000). The basal age of the Qingzhou loess is approximately synchronous with the Xiashu loess in the middle-lower reaches of the Yangtze River (Li et al., 2001; Li et al., 2002).

\subsection{Clay mineral analysis}

The X-ray diffraction patterns of clay minerals are given in Fig. 4. The patterns of each sample after different treatments clearly show that the clay minerals of

Table 1 OSL ages of the loess in the Qingzhou profile

\begin{tabular}{cccccccc}
\hline Depth $(\mathrm{m})$ & $\mathrm{U}(\mathrm{mg} / \mathrm{kg})$ & $\mathrm{Th}(\mathrm{mg} / \mathrm{kg})$ & $\mathrm{K}(\%)$ & Water content $(\%)$ & Dose rate $(\mathrm{Gy} / \mathrm{ka})$ & De/Gy & OSL age $(\mathrm{ka})$ \\
\hline 2.1 & $2.09 \pm 0.21$ & $10.64 \pm 0.23$ & 2.18 & 22.0 & $3.40 \pm 0.11$ & $2.93 \pm 0.10$ & $219.4 \pm 11.2$ \\
7.1 & $1.92 \pm 0.20$ & $10.17 \pm 0.22$ & 1.76 & 22.0 & $74.0 \pm 1.0$ & $3.29 \pm 0.11$ & $608.0 \pm 3.0$ \\
10.5 & $2.06 \pm 0.22$ & $11.55 \pm 0.25$ & 2.04 & 22.0 & $185.1 \pm 6.5$ \\
\hline
\end{tabular}


Qingzhou loess are mainly illite, secondly are smectite, chlorite and kaolinite. The semi-quantitative results (Table 2) also indicate that the clay minerals of the Qingzhou loess are mainly composed of illite, which is similar to that of the Mid-Pleistocene loess in Chinese Loess Plateau (CLP) (Liu, 1985; Peng et al., 2007). The Qingzhou loess contains more smectite, less chlorite and kaolinite compared with Malan loess of Xifeng (Peng et al., 2007). The ratios between illite and kaolinite in the Qingzhou loess are 15.9 and 20.2, respectively, which are much higher than that of the Xifeng loess (8.8).

\section{Discussion}

So far, many studies have suggested that the Qingzhou loess are eolian origin and the eolian materials are mainly from the loose deposits covering the Yellow River's fluvial plain and the exposed Bohai Bay shelf on the northern region, secondly from the northwest inland arid areas, and little from the in-situ weathering materials of local basal rocks (Cao et al., 1987; Zheng, 1994; Wang et al., 1999; Liu et al., 2000; Zhang et al., 2004; Peng et al., 2007). These opinions were mainly derived from the comparison of the grain-size characteristics between the Qingzhou loess and the CLP loess. The clay mineral analysis showed that the Qingzhou loess is composed mainly of illite, similar to that of the CLP loess. However, the Qingzhou loess contains more amount of smectite and has higher illite/kaolinite ratios than Xifeng loess, implying dif- ferent clay mineral composition between Qingzhou and CLP loess. As the analyzed samples are nearly unaffected by weathering and pedogenesis, representing the protoliths, this difference of clay mineral composition further supports the original speculation that material sources of Qingzhou loess are mainly from the Yellow River fluvial plain and the exposed Bohai Bay shelf.

The chronological result showed that the basal age of the Qingzhou loess is about $500 \mathrm{ka}$. There is no report about the eolian deposits which is older than the Qingzhou loess, and we didn't find any older ones during field observation in the whole Shandong province, indicating that the loess in Qingzhou region may start from Mid-Pleistocene. Previous studies about the Late-Pleistocene loess along the Bohai Bay (Cao et al., 1987; Han, 1987; Yu, 1999) suggested that Bohai Bay shelf could expose and became part of the arid and semi-arid area during glacier period along with the sea surface fall, consequently, the exposed and weathered marine sediments became the main source. Similarly, the basal age of the Qingzhou loess is about $500 \mathrm{ka}$, which may indicate that the exposed Bohai Bay shelf during glacier period and the Yellow River's fluvial plain had provided the materials for Qingzhou loess at that time. Additionally, some drill archives showed that there are several times of large-scale transgression and withdrawal since Mid-Pleistocene accompanying with vast marine sediments (Zhuang et al., 1999; Yao et al., 2006; Xiao et al., 2008). The coincidence be-
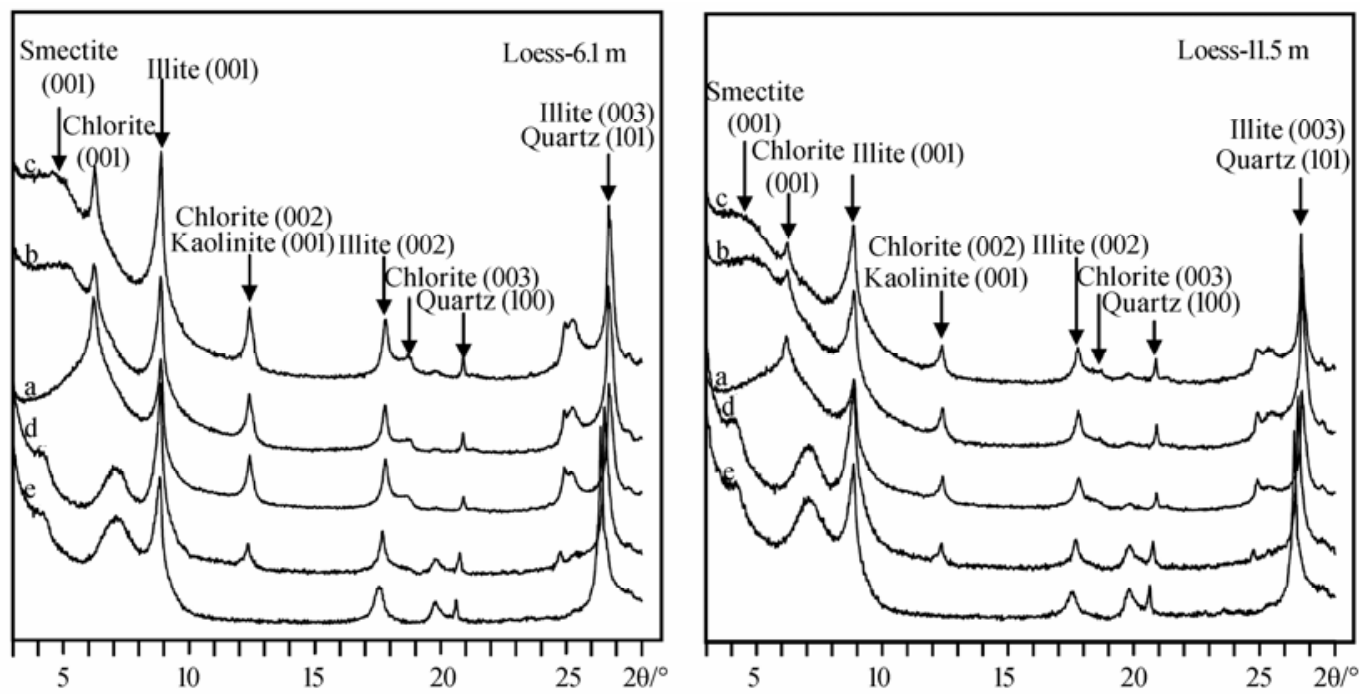

Fig. 4 XRD Diagrams of $<2 \mu \mathrm{m}$ fractions from Qingzhou loess profile $\mathrm{a}=\mathrm{MgCl}_{2} ; \mathrm{b}=\mathrm{MgCl}_{2}+$ ethylene glycol; $\mathrm{c}=\mathrm{MgCl}_{2}+$ glycerol; $\mathrm{d}=\mathrm{MgCl}_{2}+400^{\circ} \mathrm{C} ; \mathrm{e}=\mathrm{MgCl}_{2}+550^{\circ} \mathrm{C}$ 
Table 2 The clay mineral contents of the Qingzhou loess and the Xifeng loess (Peng et al., 2007)

\begin{tabular}{|c|c|c|c|c|c|c|}
\hline \multirow{2}{*}{ Samples } & \multirow{2}{*}{$\begin{array}{c}\text { Length } \\
\text { (m) }\end{array}$} & Illite & Smectite & Chlorite & Kaolinite & \multirow{2}{*}{ Illite/Kaolinite } \\
\hline & & \multicolumn{4}{|c|}{$(\%)$} & \\
\hline WF245 & 6.1 & 69.2 & 19.6 & 6.9 & 4.4 & 15.9 \\
\hline WF460 & 11.5 & 73.7 & 18.6 & 3.8 & 3.9 & 19.5 \\
\hline \multicolumn{2}{|c|}{ Xifeng loess $(n=5)$} & 67.2 & 5.8 & 18.2 & 8.8 & 8.8 \\
\hline
\end{tabular}

tween the basal age of the Qingzhou loess and the beginning of large-scale transgression around Bohai Bay further indicates that the formation of the Qingzhou loess is related to the regional environmental evolution of the Bohai Bay region.

It is noteworthy that the beginning of eolian deposits in Qingzhou region since Mid-Pleistocene is approximately synchronous to the beginning of Xiashu loess along the middle-lower reaches of Yangtze River (Li et al., 2001; Li, 2002) that is far away from Chinese Loess Plateau, consistent with the global climate change in Mid-Pleistocene. As the global climate further became cold since $0.8 \mathrm{Ma}$ (Lisiecki and Raymo, 2005), the expansion of global ice volume had produced profound effect on climate in the mid-high latitudes regions. This global cooling is expected to strengthen the Asian winter monsoon and enhance the aridity of northwest region, thus the eolian dust carrying by cold and dry current during glacier period can reach the Yangtze River region (Liu et al., 1997). Also, the eolian dust from northwest regions can be carried by high-level current and reach the Shandong region, which becomes another material provenance of the Qingzhou loess. In this sense, the formation of the Qingzhou loess is not merely related to the regional environment, but also to the global climate change since Mid-Pleistocene.

\section{Conclusion}

In this paper the chronology and mineralogy of the Fujia village's loess profile in Qingzhou region were analyzed, and the major conclusions are as follows:

(1) The magnetostratigraphic results showed that the Brunhes/Matuyama (B/M) reversal boundary is not recognized in the Fujia village profile, suggesting that the basal age of the Qingzhou loess is younger than $0.78 \mathrm{Ma}$. By linear-extrapolation of the sedimentation rate based on the OSL ages, the basal age of the Qingzhou loess was $500 \mathrm{ka}$.

(2) The clay mineral composition of the Qingzhou loess are dominated by illite, then by smectite, chlorite and kaolinite, similar to those of the Chinese Loess Plateau, but the content of smectite and the ratio of illite/kaolinite are much higher, indicating the different clay mineral composition, supporting the previous study that the Qingzhou loess are mainly from the Bohai Bay shelf and the Yellow River fluvial plain.

(3) The chronological study showed that the basal age of the Qingzhou loess is about $500 \mathrm{ka}$, implying that the exposed Bohai Bay shelf during glacier period and the Yellow River fluvial plain had provided source materials for Qingzhou loess at that time. Besides, the forming age of the Qingzhou loess is close to that of the Xiashu loess and both are corresponding to global cooling, indicating that the origin of the Qingzhou loess has close relationship with the global climate change since Mid-Pleistocene.

\section{Acknowledgements}

The research was funded by the National Natural Science Foundation of China (41072260 and 40402026).

\section{References}

Cao J X, Li P Y, Shi N. 1987. Loess of Miaodao Islands in Shandong. Science in China: Series B, 10(10): 1117-1122.

Chamley H. 1989. Clay Sedimentology. Berlin: Springer-Verlag, 21-50. Han J T. 1987. Study on the Loess in Penglai district, Shandong province. In: Liu T S. Aspects of Loess Research. Beijing: China Ocean Press, 76-84.

Kirschvink J L. 1980. The least-squares line and plane and the analysis of palaeomagnetic data. Geophysical Journal of the Royal Astronomical Society, 62(3): 699-718.

Li X S, Yang D Y, Lu H Y. 2001. Grain-size features and genesis of the Xiashu loess in Zhenjiang. Marine Geology \& Quaternary Geology, 21(1): 25-31.

Li X S, Yang D Y. 2002. Magnetic susceptibility features and environmental records of the Xiashu Loess in Zhenjiang, Jiangsu province. Journal of Desert Research, 22(1): 27-32.

Lisiecki L E, Raymo M E. 2005. A Pliocene-Pleistocene stack of 57 globally distributed benthic $\delta^{18} \mathrm{O}$ records. Paleoceanography, 20, PA1003, doi: 10.1029/2004PA001071.

Liu L J, Li P Y, Wang Y J. 2000. The grain-size properties and genesis of the loess in central Shandong province. Marine Geology and Qua- 
ternary Geology, 20(1): 81-86.

Liu T S. 1965. The Loess Deposits in China. Beijing: Science Press, $1-55$.

Liu T S. 1985. Loess and Environment. Beijing: China Ocean Press, $1-481$.

Liu T S. 1997. Quaternary Environment. Beijing: Science Press, 195-196.

Lu H Y, Wang X Y, An Z S, et al. 2004. Geomorphologic evidence of phased uplift of the northeastern Qinghai-Tibet Plateau since 14 million years ago. Science in China: Series D, 47: 822-833.

Lu Y C, Zhao H. 1991. Thermoluminescence dating of the late Quaternary loess-paleosol sequence at the Jiezhichun section, Weinan county, Shaanxi province. Geological Review, 37(4): 356-362.

Peng S Z, Gao Z D, Wu X P, et al. 2007. Grain-size distribution and genesis of loess in the Qingzhou area, Shandong. Journal of Geomechanics, 13(4): 315-321.

Peng S Z, Guo Z T. 2007. Clay mineral composition of the Tertiary Red Clay and the Quaternary loess-paleosols as well as its environmental implication. Quaternary Sciences, 27(2): 277-285.

Stevens T, Armitage S J, Lu H Y, et al. 2006. Sedimentation and diagenesis of Chinese loess: implications for the preservation of continuous, high-resolution climate records. Geology, 34(10): 849-852.
Wang S J, Zhang C J, Liu H K. 1999. Advances on the Quaternary geological study in Shandong province. Geology of Shandong, 6(15): $2-8$.

Xiao G Q, Guo Z T, Chen Y K, et al. 2008. Magnetostratigraphy of BZ1 bore hole in west coast of Bohai Bay, northern China. Quaternary Sciences, 28(5): 907-917.

Yao Z Q, Guo Z T, Chen Y K, et al. 2006. Magnetostratigraphy of marine-ferruginous facies deposits in Bohai Bay. Marine Geology and Quaternary Geology, 26(1): 9-15.

Yu H J. 1999. A new exploration on the origin of loess in the shelf area of the eastern China seas. Quaternary Sciences, 7(4): 367-372.

Zhang Z L, Xin L J, Nie X H. 2004. A summary of loess researches in Shandong. Scientia Geographica Scinica, 24(6): 746-752.

Zhao S L, Yu H J, Liu J Q. 1997. Origin, development and evolutionary model of shelf desertization environment in late stage of Upper Pleistocene. Science in China: Series D, 256(2): 207-214.

Zheng H H, Zhu Z Y, Huang B L, et al. 1994. A study on loess geochronology of Shandong Peninsula and northern part of Jiangsu and Anhui Provinces. Marine Geology and Quaternary Geology, 14(1): 64-68.

Zhuang Z Y, Xu W D, Liu D S, et al. 1999. Division and environmental evolution of Late Quaternary marine beds of S3 Hole in the Bohai Sea. Marine Geology \& Quaternary Geology, 19(2): 27-35.

\section{A Checklist on the Distribution of the Birds in Xinjiang was published}

A book, A Checklist on the Distribution of the Birds in Xinjiang, was published by Science Press recently, which was mainly edited by Prof. Ming MA from Xinjiang Institute of Ecology and Geography, Chinese Academy of Sciences.

The book summaries the observations of birds in Xinjiang, Western China, including the Chinese name, Latin name, English name, subspecies name, distribution area, and ecological behavior. A total of 453 bird species (there are also 145 subspecies), which accounts for $34 \%$ of Chinese birds, and belongs to 21 orders, 65 families and 196 genera, have been recorded in Xinjiang. Ninety species of birds that are doubtful or problematic are listed and described in the appendix. All the literatures related to the Xinjiang avifauna have been rechecked in the appendix. Finally, 576 references were attached to the checklist.

The book provides good references for scientists, teachers, students and managers, who are engaged in researches on the agriculture, farming, forest, environment, wild animal and nature reserve managements. 